\title{
Overeating, weight gain and lean body mass-is dietary protein content the key?
}

W hen healthy individuals overeat, the amount of weight gain is reduced if the diet has a lowprotein content; however, this diet also results in a loss of lean body mass and the same increase in fat mass as with normalprotein or high-protein diets. These data were revealed in a new study published in JAMA.

High food intake contributes to a positive energy balance that, over an extended period, can result in the development of obesity. However, the amount of weight gain that results from overeating is highly individual and the reasons for this individuality remain an enigma. The protein content of food overeaten might affect weight gain-a hypothesis investigated by Bray et al. in this single-blind, randomized, controlled study.

"A calorie is a calorie-or is it? That was part of the question we tried to answer in this highly controlled study of different dietary protein levels during overfeeding in healthy men and women who were normal weight or slightly overweight," explains lead researcher George Bray of the Pennington Biomedical Research Center, USA.

The researchers randomly allocated 25 healthy individuals of 18-35 years of age and with a BMI of $19-30 \mathrm{~kg} / \mathrm{m}^{2}$ to be overfed a low-protein diet ( $5 \%$ of energy from protein), a normal-protein diet (15\%) or a high-protein diet (25\%) for 8 weeks. The percentage of energy content from carbohydrate was constant between the different diets (41-42\%), whereas that from fat varied. The group of participants included both men and women and was varied in terms of ethnicity. Participants stayed in an inpatient metabolic unit during the 10 weeks to 12 weeks of the study, which included a run-in period of 13-25 days during which individuals received an isocaloric diet (15\% of energy from protein) that had been calculated to be weight stabilizing by energy expenditure measurements.
During the 8-week overfeeding period, individuals had an energy intake that was approximately $40 \%$ above the intake calculated as their maintenance energy requirement during the run-in period.

All participants gained weight but the mean weight gain for the low-protein diet group $(3.16 \mathrm{~kg}$ ) was $\sim 50 \%$ of that for the other two diet groups; gains were $6.05 \mathrm{~kg}$ and $6.51 \mathrm{~kg}$ with the normal-protein and high-protein diets, respectively. Of note, the reduced weight gain in the low-protein diet group resulted from an incapacity to increase lean body mass, which did increase in individuals overfed the other two diets. By contrast, fat mass increases were not significantly different between the three groups, although, interestingly, an average $200 \mathrm{~g}$ of excess fat was gained in individuals in the low-protein diet group.

Overeating did not significantly affect resting energy expenditure or total energy expenditure if the diet was low in protein. By contrast, both types of energy expenditure increased during overfeeding with normal-protein or high-protein diets. This increase occurred despite a lack of change in physical activity levels between baseline and during overeating. The researchers used metabolic calculations to discover why energy expenditure differed by the protein content of the overfed diet. They found that the percentage of extra

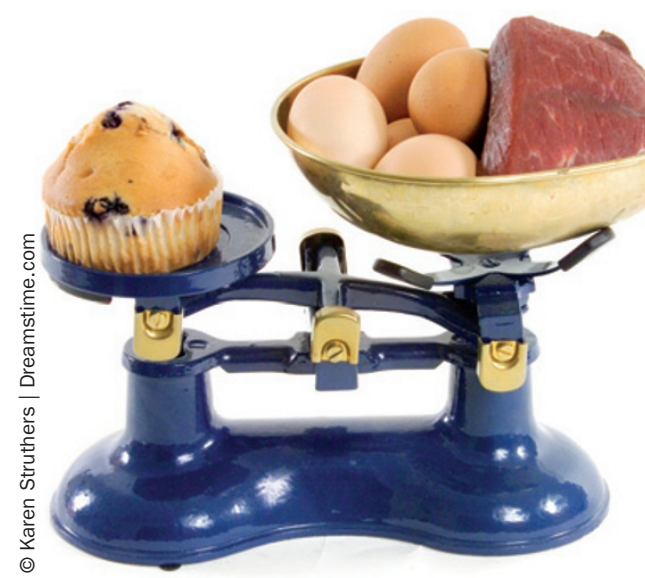

energy stored as fat was $>90 \%$ for the lowprotein diet but only $\sim 50 \%$ for the diets with normal or high protein content. For these last two diets, most of the remaining energy was consumed by increased dietinduced thermogenesis, probably related to protein synthesis.

"We knew that too little protein in the diet during weight-loss diets (undereating) is detrimental for health as it causes excessive loss of lean body mass from muscle and other vital organs and tissues, but this study shows that even during overeating too little protein causes loss of lean tissue and reduces the rate of metabolism. So, this result emphasizes the importance of protein in the diet for health and body-weight regulation," comments Arne Astrup of the University of Copenhagen, who was not involved in this study.

"From a public health perspective," Astrup continues, "the study has, in my view, little relevance to guide the consumers to select the most healthy diet to prevent weight gain and cause weight loss because the most important property of dietary protein is its much stronger satiating effect that, in many studies, has been shown to make overeating much more difficult. The design of this study was fixed caloric overfeeding, so the appetite regulation of the participants was put out of play."

The findings, however, provide food for thought. "For fat and carbohydrate a calorie is a calorie, this study showed.

But protein was different. Changing dietary protein over a range of $5 \%$ to $25 \%$ did not affect

fat storage, but it did affect the increase in lean body mass and thermogenesis," concludes Bray.

Carol Wilson

Original article Bray, G. A. et al. Effect of dietary protein content on weight gain, energy expenditure, and body composition during overeating: a randomized controlled trial. JAMA 307, 47-55 (2012) 